\title{
Effect of second phase particles on mechanical properties and grain growth in a CoCrFeMnNi high entropy alloy
}

\author{
M.V. Klimova*, D.G. Shaysultanov, S.V. Zherebtsov, N.D. Stepanov \\ Laboratory of Bulk Nanostructured Materials, Belgorod National Research University, Pobeda 85, Belgorod 308015, Russia
}

\section{A R T I C L E I N F O}

\section{Keywords:}

High entropy alloys

Phase transformations

Grains and interfaces

Electron microscopy

Stress/strain measurements

\begin{abstract}
A B S T R A C T
Effect of annealing of a cold-worked CoCrFeMnNi alloy at temperatures of $500-900{ }^{\circ} \mathrm{C}$ for $1-50 \mathrm{~h}$ on the structure and mechanical properties was studied in the present work. Annealing for an hour resulted in: i) recrystallization of the face-centered cubic (fcc) matrix at $600-900{ }^{\circ} \mathrm{C}$; ii) precipitation of a Cr-rich body-centered cubic (bcc) phase at $500-700{ }^{\circ} \mathrm{C}$ or a sigma phase particles at $600-800{ }^{\circ} \mathrm{C}$. Moreover, an increase in the annealing time to $50 \mathrm{~h}$ at $600{ }^{\circ} \mathrm{C}$ resulted in a continuous growth of both the fcc grans and bcc/sigma particles and in an increase in the fraction of the sigma phase at the expense of the bcc phase particles. The fcc grains growth was found to be controlled by the pinning effect of the second phase particles. Soaking for an hour at $500-600{ }^{\circ} \mathrm{C}$ resulted in a substantial increase in strength of the alloy due to the second phases precipitation. Meanwhile annealing at the higher temperatures as well as an increase in the annealing time at $600{ }^{\circ} \mathrm{C}$ resulted in softening; however, even after $50 \mathrm{~h}$ annealing, the alloy demonstrated reasonably high strength. In the latter case fine fcc grains, preserved due to the pinning effect by the second phases particles, contributed to strength mainly.
\end{abstract}

\section{Introduction}

The so-called high-entropy alloys have recently emerged as a new class of advanced metallic materials with complex, multicomponent chemical composition. It is believed that among the extreme vastness of possible compositions and structures some of these alloys can possess unique properties [1]. Some of the promising HEAs are those which base on $3 d$ transition elements and have a face-centered cubic (fcc) structure [2]; a representative of this class is the equiatomic CoCrFeMnNi alloy $[2,3]$. It has a single fcc random solid solution phase structure which is stable at high temperatures $\left(\geq 900^{\circ} \mathrm{C}\right)$ [4-8]. The alloy has also very high ductility and fracture toughness at room and cryogenic temperatures, making it promising for cryogenic applications [9-11]. The yield strength of the alloy at room temperature is rather low, however. Precipitation strengthening due to alloying by additional elements, such as $\mathrm{Al}, \mathrm{Ti}, \mathrm{C}$, etc., was found to be particularly effective [12-20].

Meanwhile, it is well established that the "pure" CoCrFeMnNi alloy is also prone to the second phases precipitating after heat treatments (annealing) at temperatures below $900{ }^{\circ} \mathrm{C}$ [4-8]. These precipitations included sigma, body-centered cubic (bcc), $\mathrm{L}_{0}$, and $\mathrm{B} 2$ phases depending on the exact conditions (i.e. time and temperature of the annealing treatment). It was shown earlier with respect to other HEAs that, for example, the sigma phase can be effectively utilized for strengthening $[21,22]$. However, only a few studies have examined the influence of the second phase precipitations on the mechanical behavior of the CoCrFeMnNi alloy $[6,23]$.

The second phase(s) particles can also affect various processes in the fcc matrix, for example grain growth. It was recently demonstrated that in $\mathrm{CoCrFeNi}(\mathrm{Mn}, \mathrm{Al}, \mathrm{C}$ ) alloys second phases precipitations (mostly B2 phase particles) can effectively impede grain growth and can result in the formation of a fine-grained microstructure [24-26]. Alloys with the fine-grained recrystallized microstructure can have an attractive combination of strength, ductility, and fatigue resistance. Meanwhile, it is unclear if the same approach can work in the "pure" CoCrFeMnNi alloy. Moreover, the understanding of both grain growth and particle coarsening in HEAs is lacking at the moment [13,20,25,27-30], despite the fact that both of these processes are crucial for the production of alloys with desirable microstructures and properties.

Therefore, in the present work, we have performed a detailed investigation of structure and mechanical properties of the CoCrFeMnNi high-entropy alloy after cold rolling and subsequent annealing at $500-900{ }^{\circ} \mathrm{C}$ for $1-50 \mathrm{~h}$. The aim of the investigation was (i) to gain insight into the kinetics of both grain growth and second phases coarsening in the alloy as well as to establish their interdependence; (ii) to estimate the effect of the second phases precipitation on mechanical

\footnotetext{
* Corresponding author.

E-mail address: klimova_mv@bsu.edu.ru (M.V. Klimova).
} 
properties of the alloy.

\section{Materials and methods}

The equiatomic CoCrFeMnNi alloy $\left(\mathrm{Co}_{20.6} \mathrm{Cr}_{19.9} \mathrm{Fe}_{19.5} \mathrm{Ni}_{20.9} \mathrm{Mn}_{19.1}\right.$ in at\%) was produced by vacuum arc melting and homogenized at $1000{ }^{\circ} \mathrm{C}$ for $24 \mathrm{~h}$. The homogenized alloy was cold-rolled to $80 \%$ reduction and then annealed at $500{ }^{\circ} \mathrm{C}, 600{ }^{\circ} \mathrm{C}, 700^{\circ} \mathrm{C}, 800{ }^{\circ} \mathrm{C}$ or $900{ }^{\circ} \mathrm{C}$ for $1 \mathrm{~h}$, and for $1,2,510$ or $50 \mathrm{~h}$ at $600^{\circ} \mathrm{C}$; the annealing was followed by air cooling. Additional details of the alloy production and processing can also be found elsewhere $[6,21]$.

The microstructure of the alloy was studied by scanning (SEM) and transmission (TEM) electron microscopy. Samples for SEM observations were prepared by careful mechanical polishing. SEM studies were performed using FEI Quanta 600 FEG microscope equipped with a backscattered electron (BSE) detector. Samples for TEM analysis were prepared by conventional twin-jet electro-polishing of mechanically pre-thinned to $100 \mu \mathrm{m}$ foils, using an electrolyte composed of $95 \%$ $\mathrm{C}_{2} \mathrm{H}_{5} \mathrm{OH}$ and $5 \% \mathrm{HClO}_{4}$ at a voltage of $27 \mathrm{~V}$ at room temperature. TEM investigations were performed using a JEOL JEM-2100 apparatus equipped with an X-ray energy dispersive spectrometry (EDS) detector at an accelerating voltage of $200 \mathrm{kV}$. Selected area electron diffraction (SAEDs) patterns were used for the phase identification and EDS analysis - for chemical analysis. The size/fractions of recrystallized grains and size/number of precipitates were quantified using at least 10 SEM (for grains and coarse particles) or TEM (for nanoparticles) images with low magnification. For each structural constituent in particular condition, more than $10^{3}$ individual measurements were made to obtain representative statistics. For a careful calculation of the effects of precipitates on the recrystallization behavior, the parameters of particles of different types were determined separately; e.g. sigma particles were distinguished from the bcc ones; the particles located inside the fcc grains and at grain boundaries were also evaluated separately.

Specimens with the gauge dimensions of $6 \times 3 \times 1 \mathrm{~mm}^{3}$ were used for mechanical tests which consisted in tension at a constant crosshead speed of $10^{-3} \mathrm{~s}^{-1}$ to fracture. The long axis of the specimens was aligned with the rolling direction. Elongation to fracture was determined by the measurements of spacing between marks designating the gauge length (before and after the test). At least two samples in each condition were tested. The microhardness of the specimens was examined using Vickers microhardness testing with a load of $0.2 \mathrm{~kg}$. The hardness values were averaged over at least 20 individual measurements for each data point.

\section{Results}

\subsection{Microstructure}

\subsubsection{Initial microstructure}

Microstructure of the CoCrFeMnNi alloy in the cold-rolled condition ( $80 \%$ reduction) is presented in Fig. 1. The cold-rolled alloy had a single-phase heavily-deformed lamellar microstructure composed of twin boundaries and shear bands mostly aligned with the rolling direction. The grains/subgrains transverse size was of about $70 \mathrm{~nm}$. (Fig. 1, see also [31]).

\subsubsection{Effect of isochronal annealing}

Fig. 2 illustrates the effect of annealing of the cold-rolled CoCrFeMnNi alloy at a temperature in the range of $500-900^{\circ} \mathrm{C}$ for $1 \mathrm{~h}$. Annealing at the lowest temperature $\left(500{ }^{\circ} \mathrm{C}\right)$ did not result in significant changes of microstructure in comparison to that of deformed condition; yet some bcc phase particles appeared in the fcc matrix (Fig. 2a, Table 1).

At a higher temperature $\left(600^{\circ} \mathrm{C}\right)$ the majority of the fcc matrix was found to be recrystallized with a size of the recrystallized grains of $1.3 \mu \mathrm{m}$ (Fig. 2b). The fraction of unrecrystallized areas was 0.35

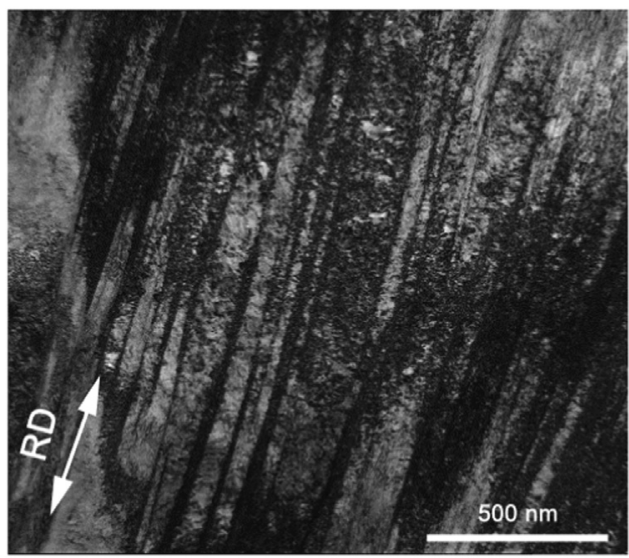

Fig. 1. TEM bright-field image of the structure of the CoCrFeMnNi alloy after $80 \%$ cold rolling.

(Table 1). In addition sigma phase particles were observed in the microstructure; sigma particles were coarser and had a rectangular shape, while the bcc particles were found to be round and very fine (Table 1). The bcc particles were distributed homogeneously; the sigma phase particles were located predominantly at the boundaries. However, some sigma particles were also found inside the fcc matrix grains. Particles of both types (bcc and sigma) were mostly composed of $\mathrm{Cr}$ (Table 2).

Further increase in annealing temperature resulted in complete recrystallization and led to a gradual increase in the fcc grain size from $2.0 \mu \mathrm{m}$ after annealing at $700{ }^{\circ} \mathrm{C}$ to $17.1 \mu \mathrm{m}-$ at $900{ }^{\circ} \mathrm{C}$ (Fig. 2c-e, Table 1). The alloy contained both the bcc and sigma particles after annealing at $700{ }^{\circ} \mathrm{C}$; yet the fraction of the bcc phase particles was significantly lower than that of the sigma phase. Only a small amount of the sigma particles was found at some grain boundaries after annealing at $800{ }^{\circ} \mathrm{C}$, and no particles were detected after annealing at $900{ }^{\circ} \mathrm{C}$. Note the presence of multiple annealing twins in fcc grains.

\subsubsection{Isothermal annealing at $600^{\circ} \mathrm{C}$}

Typical microstructures formed in the cold rolled alloy after annealing at $600{ }^{\circ} \mathrm{C}$ for $2-50 \mathrm{~h}$ are shown in Fig. 3. Annealing was accompanied by a pronounced increase in the recrystallized fraction; already after $5 \mathrm{~h}$ of annealing the recrystallized volume comprised 0.95 of a sample. At the same time recrystallized grains growth occurred; the average grain size increased from $1.3 \mu \mathrm{m}$ to $3.8 \mu \mathrm{m}$ with an increase in the annealing time from 1 to $50 \mathrm{~h}$ (Table 3). A number of near-equilibrium triple junctions of grain boundaries and annealing twins observed in Fig. 3 suggest normal grain growth as the main mechanism of microstructure evolution.

The grain growth occurred concurrently with the second phases particles coarsening (Fig. 3, Table 3), however different types of particles coarsened to a different extent. For instance, the sigma particles located at grain boundaries increased from 260 to $820 \mathrm{~nm}$ with an increase in the annealing time from 1 to $50 \mathrm{~h}$; the bcc particles under the same conditions increased from 70 to $120 \mathrm{~nm}$ only. At the same time the fraction of the bcc particles decreased from $1.2 \%$ to $0.37 \%$ (for 1-50 $\mathrm{h}$ annealing) while the sigma phase particles fraction increased from $2.0 \%$ to $7.4 \%$ after 1 and $50 \mathrm{~h}$ of annealing, respectively.

A power law function of annealing time $(\mathrm{t})$ is commonly used to calculate the grain/particle size $d \sim t^{1 / n}$ [32]. The kinetics of both fcc grain growth and particles coarsening during annealing at $600{ }^{\circ} \mathrm{C}$ is shown in Fig. 4 in a log-log scale. It is clearly seen that the size of grains, sigma particles, and bcc particles can be related to the annealing time with the growth exponent $\mathrm{n}$ of about $3.6,4$, and 7 respectively. 


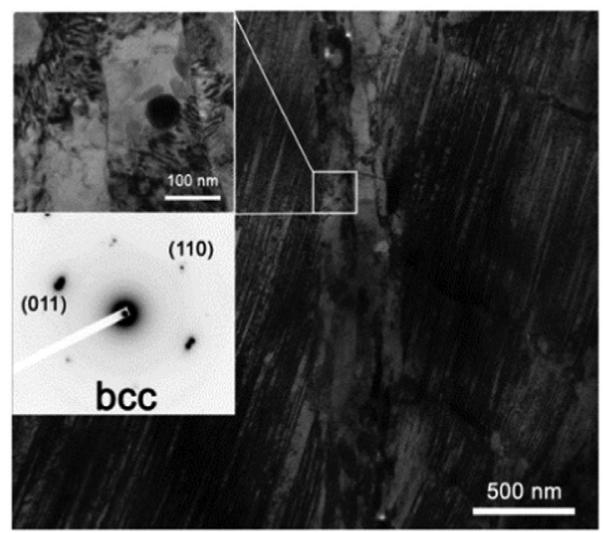

(a)

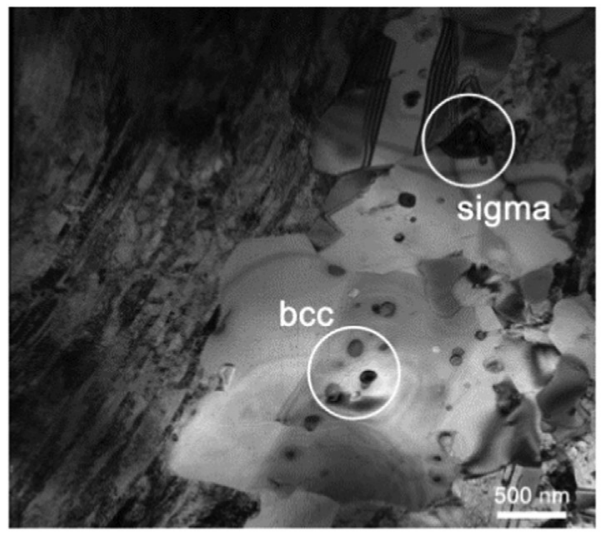

(b)

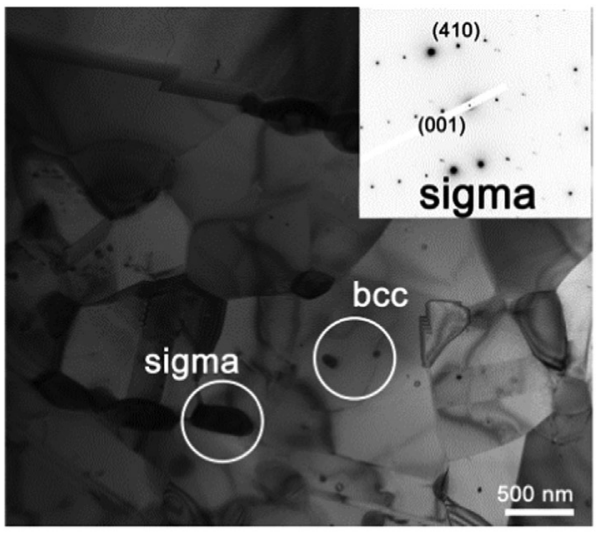

(c)

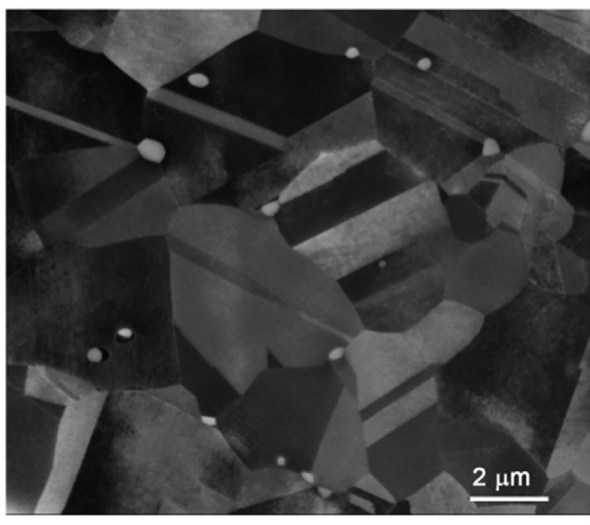

(d)

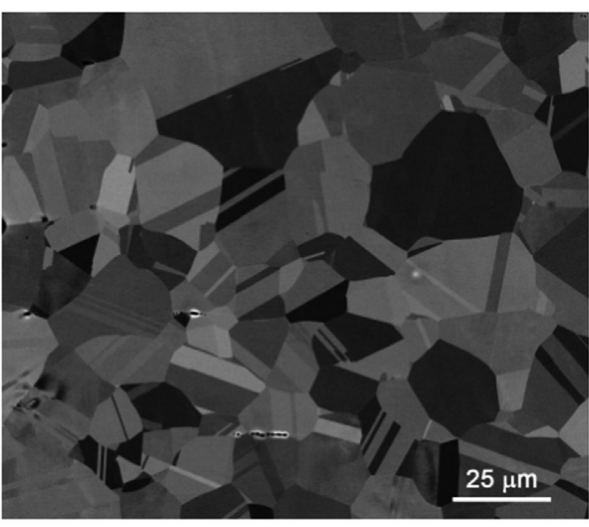

(e)

Fig. 2. Structure of the CoCrFeMnNi alloy after annealing for $1 \mathrm{~h}$ at: (a) $-500^{\circ} \mathrm{C}$; (b) $-600^{\circ} \mathrm{C}$; (c) $-700^{\circ} \mathrm{C}$; (d) $-800^{\circ} \mathrm{C}$; (e) - $900{ }^{\circ} \mathrm{C}$; (a-c) are TEM bright-field images, (d, e) - SEM-BSE images. Representative SAEDs are given in (a) and (c).

\subsection{Mechanical properties}

\subsubsection{Effect of isochronal annealing}

Fig. 5 displays the stress-strain curves of the CoCrFeMnNi alloy in different conditions. The resulting mechanical properties, namely yield strength (YS), ultimate tensile strength (UTS), uniform elongation (UE), and elongation to fracture (EF) are summarized in Table 4. In the coldrolled condition, the alloy exhibited high strength (YS = $1120 \mathrm{MPa})$, but relatively low ductility ( $\mathrm{EF}=14 \%)$. Surprisingly, annealing at 500 or $600{ }^{\circ} \mathrm{C}$ has resulted in quite a pronounced increase in strength (YS = $1290 \mathrm{MPa}$ and $1155 \mathrm{MPa}$, respectively) together with a reduction in ductility ( $\mathrm{EF}=3.6 \%$ and $6.7 \%$, respectively). Annealing at higher temperatures in the range of $700-900{ }^{\circ} \mathrm{C}$ resulted in a decrease in strength ( $\mathrm{YS}=270-585 \mathrm{MPa}$ ) and a pronounced increase in ductility $(\mathrm{EF}=43-60 \%)$.

\subsubsection{Effect of isothermal annealing}

Microhardness measurements were used to estimate the effect of
Table 2

Chemical composition of the constitutive phases in the CoCrFeMnNi alloy after 1-h annealing at $700^{\circ} \mathrm{C}$.

\begin{tabular}{llllll}
\hline Elements & Co & Cr & Fe & Mn & Ni \\
\hline Fcc matrix & 20.8 & 18.5 & 19.8 & 21.0 & 19.9 \\
Bcc particles & 17.3 & 36.5 & 18.0 & 16.1 & 12.1 \\
Sigma particles & 16.2 & 43.8 & 17.6 & 14.6 & 7.8 \\
\hline
\end{tabular}

annealing duration at $600{ }^{\circ} \mathrm{C}$ on strength of the $\mathrm{CoCrFeMnNi}$ alloys (Fig. 6). The cold-rolled alloy had a high hardness of 374 HV. Similarly to the tensile strength (Table 4), a short-time annealing (1-2 h) resulted in somewhat higher hardness of 386-393 HV. However, the alloy softened considerably with an increase in the annealing time attaining 276 $\mathrm{HV}$ after annealing for $50 \mathrm{~h}$.

To gain more insight into the effect of annealing time on mechanical behavior of the alloy, tensile testing of the specimen after 1 and $50 \mathrm{~h}$ annealing was performed (Fig. 7). As it was shown earlier (Fig. 5,

Table 1

Structure parameters of the CoCrFeMnNi alloy after 1-h annealing at different temperatures.

\begin{tabular}{|c|c|c|c|c|c|c|}
\hline Annealing temperature, ${ }^{\circ} \mathrm{C}$ & & 500 & 600 & 700 & 800 & 900 \\
\hline \multirow[t]{2}{*}{ Bcc particles } & Fraction, \% & $0.8 \pm 0.05$ & $1.2 \pm 0.20$ & $0.4 \pm 0.02$ & - & - \\
\hline & Size, $\mathrm{nm}$ & $35 \pm 15$ & $70 \pm 16$ & $75 \pm 15$ & - & - \\
\hline \multirow[t]{2}{*}{ Sigma particles } & Fraction, \% & - & $2.1 \pm 0.5$ & $2.7 \pm 0.6$ & $0.2 \pm 0.01$ & - \\
\hline & Size, nm & - & $220 \pm 115$ & $310 \pm 130$ & $420 \pm 135$ & - \\
\hline \multirow[t]{2}{*}{ Recrystallized fcc grains } & Fraction, \% & - & $65 \pm 15$ & 100 & 100 & 100 \\
\hline & Size, $\mu \mathrm{m}$ & - & $1.3 \pm 0.7$ & $2.0 \pm 0.9$ & $3.6 \pm 1.7$ & $17.1 \pm 8.2$ \\
\hline
\end{tabular}




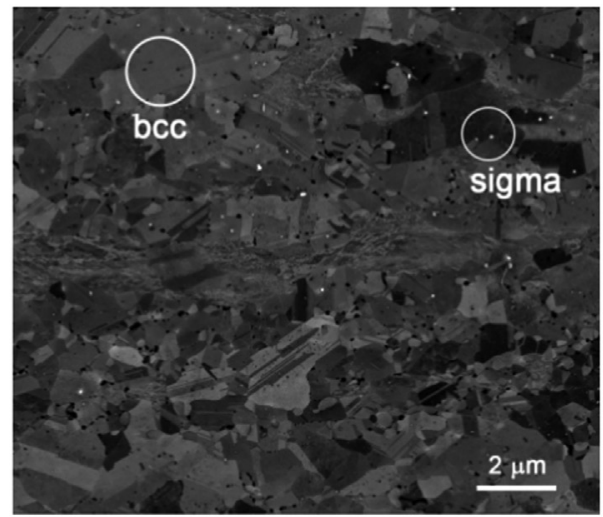

a

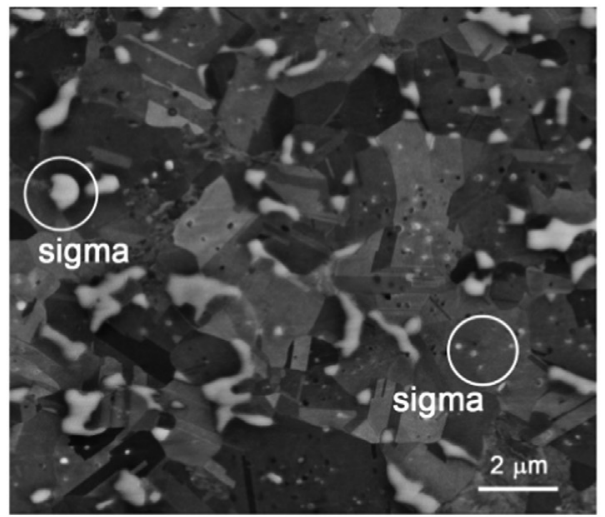

b

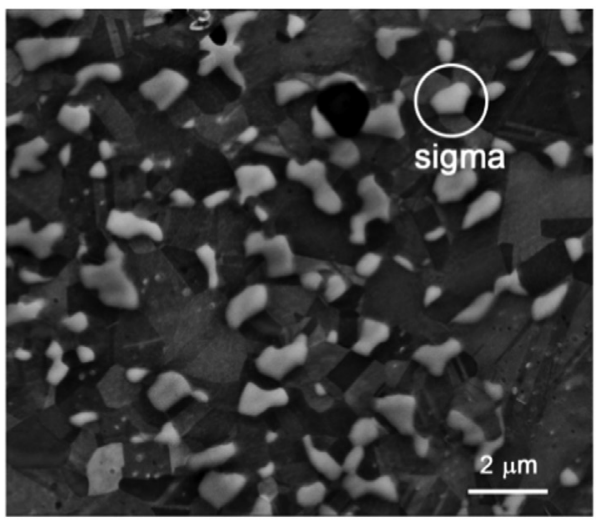

c

Fig. 3. Structure of the CoCrFeMnNi alloy after annealing at $600{ }^{\circ} \mathrm{C}$ for: (a) $-2 \mathrm{~h}$; (b) $-10 \mathrm{~h}$; (c) $-50 \mathrm{~h}$.

Table 4), after 1-h annealing the alloy had high strength but rather low ductility. An increase in the annealing time has resulted in softening and increase of ductility. However, the strength of the alloy was retained on a rather high level: YS $=685 \mathrm{MPa}$ and UTS $=880 \mathrm{MPa}$. Despite rather weak strain hardening (Fig. 6) the alloy also demonstrated modest UE of $14 \%$.

\section{Discussion}

\subsection{Microstructural response}

The obtained results shows that the annealing at $500-900{ }^{\circ} \mathrm{C}$ for $1 \mathrm{~h}$ of the cold worked CoCrFeMnNi alloy resulted in (i) recrystallization of the fcc matrix (at $600-900{ }^{\circ} \mathrm{C}$ ) and (ii) precipitation of the Cr-rich bcc (at $500-700{ }^{\circ} \mathrm{C}$ ) and sigma (at $600-800^{\circ} \mathrm{C}$ ) particles (Fig. 2, Table 1). The development of recrystallization at $\mathrm{T} \geq 600^{\circ} \mathrm{C}$ in this alloy was reported earlier several times [7,27-29,33,34]; therefore an increase in both size and fraction of recrystallized grains with increasing temperature is anticipated. The assortment of the observed second phases and the sequence of their precipitation (i.e. bcc at $500-700{ }^{\circ} \mathrm{C}$ and sigma at $600-800^{\circ} \mathrm{C}$ ) were also in agreement with previous reports $[4,6,7]$. The complex dependence of the fractions and sizes of the constitutive phases on the annealing temperature were most likely caused by an intricate relation between the kinetics (diffusion activity increases with temperature) and thermodynamic (equilibrium fraction of the second phase particles usually decreases with temperature) factors.

Meanwhile an increase in the annealing duration at $600{ }^{\circ} \mathrm{C}$ from 1 to $50 \mathrm{~h}$ led to less expected results in terms of the alloy phase composition. Namely, the fraction of the bcc phase particles decreased pronouncedly, while the sigma phase fraction increased (Table 3). It should be noted, however, that as per the CALPHAD calculation results $[35,36]$, the sigma phase is the only equilibrium phase in the alloy at $600{ }^{\circ} \mathrm{C}$ except for the fcc matrix. At the same time the sigma phase has a complex tetragonal crystal structure which retards the precipitation kinetics $[37,38]$. On the other side the disordered bcc phase (also enriched with Cr) can be a metastable intermediate phase which appeared at the

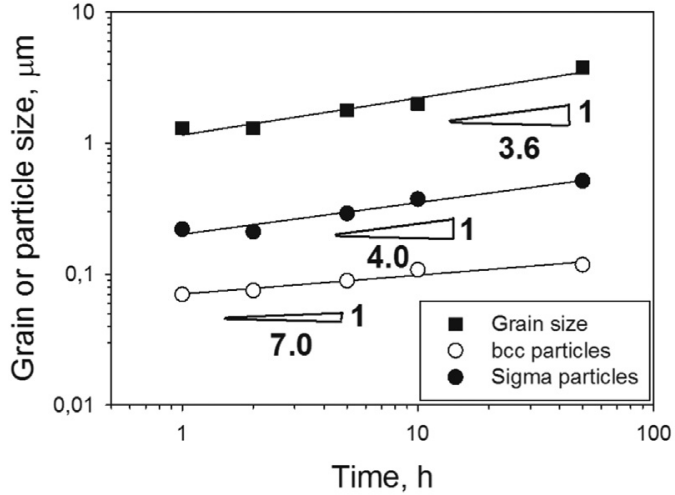

Fig. 4. Size of the fcc grains and bcc or sigma particles as a function of annealing time at $600{ }^{\circ} \mathrm{C}$.

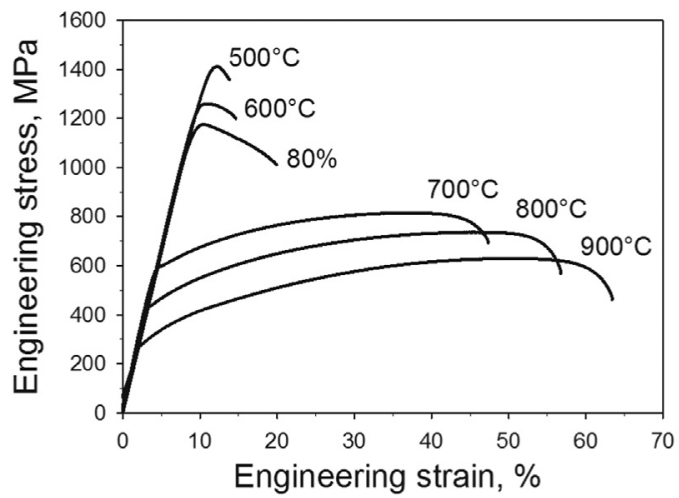

Fig. 5. Engineering stress-strain curves of the CoCrFeMnNi alloy after $80 \%$ cold rolling and subsequent annealing at $500-900{ }^{\circ} \mathrm{C}$.

Table 3

Structure parameters of the CoCrFeMnNi alloy after annealing at $600{ }^{\circ} \mathrm{C}$ for $1-50 \mathrm{~h}$.

\begin{tabular}{|c|c|c|c|c|c|c|}
\hline Annealing time, $\mathrm{h}$ & & 1 & 2 & 5 & 10 & 50 \\
\hline \multirow[t]{2}{*}{ Bcc particles } & Fraction, \% & $1.2 \pm 0.20$ & $1.0 \pm 0.13$ & $0.73 \pm 0.11$ & $0.54 \pm 0.07$ & $0.37 \pm 0.03$ \\
\hline & Size, $\mathrm{nm}$ & $70 \pm 16$ & $76 \pm 23$ & $89 \pm 31$ & $108 \pm 41$ & $118 \pm 47$ \\
\hline \multirow[t]{2}{*}{ Sigma particles } & Fraction, \% & $2.0 \pm 0.5$ & $2.6 \pm 0.8$ & $3.9 \pm 1.4$ & $5.4 \pm 2.1$ & $7.4 \pm 1.9$ \\
\hline & Size, $\mathrm{nm}$ & $220 \pm 115$ & $211 \pm 132$ & $292 \pm 180$ & $374 \pm 250$ & $515 \pm 380$ \\
\hline \multirow[t]{2}{*}{ Recrystallized fcc grains } & Fraction, \% & $65 \pm 15$ & $72 \pm 5$ & $95 \pm 5$ & 100 & 100 \\
\hline & Size, $\mu \mathrm{m}$ & $1.3 \pm 0.7$ & $1.3 \pm 0.4$ & $1.8 \pm 0.6$ & $2.0 \pm 0.8$ & $3.8 \pm 1.9$ \\
\hline
\end{tabular}


Table 4

Mechanical properties of the CoCrFeMnNi alloy after $80 \%$ cold rolling and subsequent annealing at $500-900^{\circ} \mathrm{C}$ : yield strength (YS), ultimate tensile strength (UTS), uniform elongation (UE), and elongation to fracture (EF).

\begin{tabular}{lcccc}
\hline Condition & YS, MPa & UTS, MPa & UE, \% & EF, \% \\
\hline $80 \%$ rolling & 1120 & 1175 & 1.5 & 14.0 \\
$80 \%$ rolling + annealing $500^{\circ} \mathrm{C}$ & 1290 & 1415 & 1.1 & 3.6 \\
$80 \%$ rolling + annealing $600^{\circ} \mathrm{C}$ & 1135 & 1260 & 1.8 & 6.7 \\
$80 \%$ rolling + annealing $700^{\circ} \mathrm{C}$ & 585 & 815 & 31.7 & 42.7 \\
$80 \%$ rolling + annealing $800^{\circ} \mathrm{C}$ & 425 & 735 & 40.2 & 52.5 \\
$80 \%$ rolling + annealing $900^{\circ} \mathrm{C}$ & 270 & 630 & 46.2 & 60.5 \\
\hline
\end{tabular}

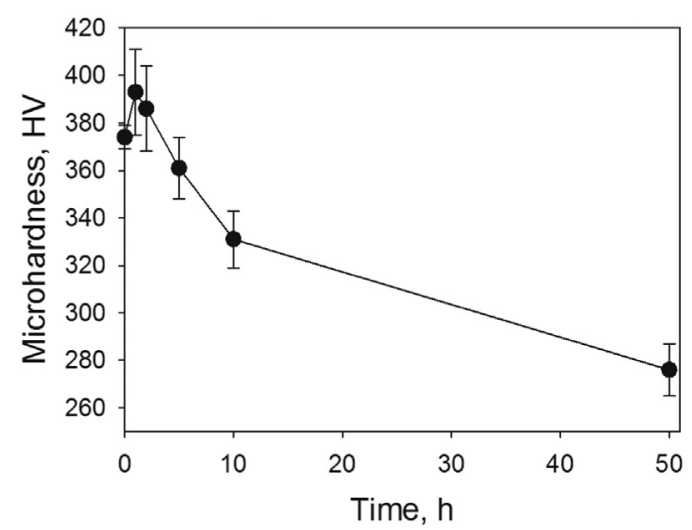

Fig. 6. Dependence of the CoCrFeMnNi alloy microhardness on annealing time at $600{ }^{\circ} \mathrm{C}$.

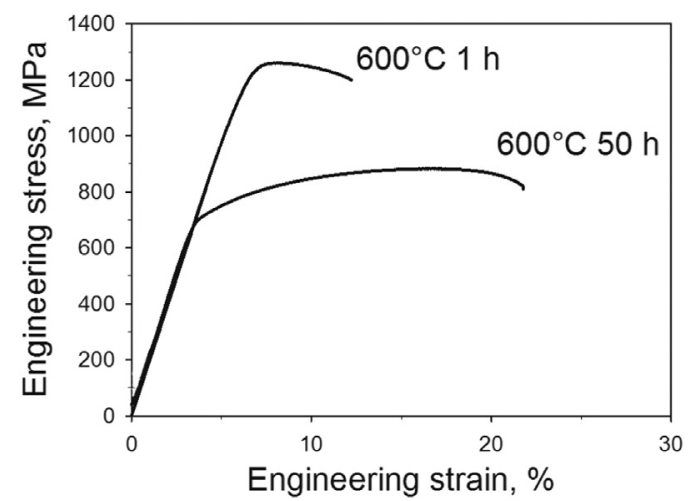

Fig. 7. Tensile stress-strain curve of the CoCrFeMnNi alloy on the annealing time at $600{ }^{\circ} \mathrm{C}$ for 1 and $50 \mathrm{~h}$.

initial stages of annealing at $600{ }^{\circ} \mathrm{C}$ due to the fcc solid solution decomposition. During further annealing the bcc phase was gradually replaced with the equilibrium sigma phase.

The changes in the fractions of the constitutive phases were accompanied by grains/particles coarsening (Table 3, Fig. 4). Coarsening can be controlled by volume diffusion if the growth exponents $n=3$ [39], or by diffusion along grain boundaries if $n=4$ [40]. In the present case, the sigma particles coarsening seems to be controlled mainly by grain boundary diffusion with $n=4$ (Fig. 4) taking into account their preferable location at grain boundaries. Meanwhile the bcc particles exhibited much slower coarsening kinetics with $n=7$, that can be associated with the phase dissolution during annealing due to the nonequilibrium nature. The fcc grains coarsening kinetics $(n=3.6)$ only slightly faster than that of the grain boundary sigma particles thereby suggesting the main contribution of grain boundary diffusion to fcc grains growth. It should be noted that the found fcc grain growth exponent is higher than that reported for annealing in the single-phase region at $850-950^{\circ} \mathrm{C}(\mathrm{n}=3)$ [27].

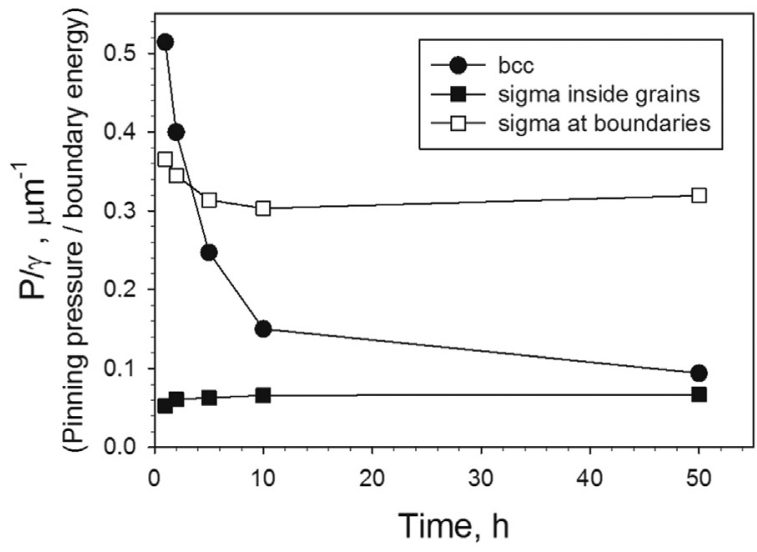

Fig. 8. Grain boundary energy normalized pinning pressures from different particles in the CoCrFeMnNi alloy during annealing at $600{ }^{\circ} \mathrm{C}$ as a function of annealing time.

Usually the coarsening kinetics in two-phase compositions with the pinning effect of the second phase particles can be described by the well-known Zener drag mechanism. Following Zener's original consideration, [41] the pinning pressure $P_{z}$ on a boundary caused by homogeneously distributed spherical particles can be derived as:

$P_{Z}=3 \gamma \frac{F_{v}}{d}$

where $\gamma$ is the boundary surface energy per unit area, and $F v$ and $d$ are the fraction and size of dispersed particles, respectively. When the particles are located at the boundaries, the pinning pressure $P_{B}$ on a boundary depends on the ratio of particles and grains size [42] and can be evaluated as:

$P_{B}=\gamma \frac{F v_{b} D}{d^{2}}$,

where $D$ is the grain size, $F v_{b}$ is the fraction of particles at grain boundaries.

The pinning pressure on grain boundaries caused by different kinds of precipitates after different annealing times was calculated (Fig. 8) using the input parameters for the bcc particles from Table 3 and for sigma particles from Table 5. Since the sigma phase particles were found both inside grains and at grain boundaries, the pinning pressures for these cases were calculated separately using either Eq. (1) for the homogeneously distributed sigma particles or Eq. (2) for the grain boundary particles, respectively. The bcc particles pinning effect was also calculated using Eq. (1).

At relatively small annealing times (1-2h), the maximal pinning pressure was provided by randomly distributed bcc particles due to their small size (Table 3). With increasing time the bcc precipitates induced $P_{z}$ reduced rapidly, almost reaching the values for the intragranular sigma precipitates which exhibited the smallest effect for all annealing times. In contrast, the pinning pressures $P_{B}$ attributed to the grain boundary sigma particles only slightly decreased with increasing the annealing time. Starting from $5 \mathrm{~h}$ annealing, the sigma precipitates provided the highest pinning pressures $P_{B}$ (Fig. 8) obviously restricting grain growth during annealing.

The Zener limiting grain size can be calculated using the following equation [43]:

$D_{Z}=a \frac{2 d}{3 F_{v}}$

where $\alpha$ is a scaling factor, $d$ and $F_{v}$ are respectively size and fraction of particles. The relationship between the experimental fcc grain size (Table 2) and the average size / average fraction of all the particles ( $d$ / $F_{v}$ ) ratio is plotted in Fig. 9.

Fig. 9 shows that the fcc grain size is proportional to the $d / F_{v}$ ratio of 
Table 5

Sigma phase particles parameters of the CoCrFeMnNi alloy after annealing at $600{ }^{\circ} \mathrm{C}$ for $1-50 \mathrm{~h}$.

\begin{tabular}{|c|c|c|c|c|c|c|}
\hline Annealing time, hours & & 1 & 2 & 5 & 10 & 50 \\
\hline \multirow{2}{*}{ Sigma particles inside grains } & Fraction, $\%$ & $0.14 \pm 0.04$ & $0.18 \pm 0.05$ & $0.23 \pm 0.08$ & $0.27 \pm 0.09$ & $0.35 \pm 0.11$ \\
\hline & Size, nm & $76 \pm 16$ & $91 \pm 18$ & $110 \pm 13$ & $123 \pm 11$ & $157 \pm 20$ \\
\hline \multirow[t]{2}{*}{ Sigma particles at grain boundaries } & Fraction, $\%$ & $1.9 \pm 0.7$ & $2.4 \pm 0.8$ & $3.7 \pm 1.4$ & $5.1 \pm 2.1$ & $7.0 \pm 2.2$ \\
\hline & Size, nm & $260 \pm 47$ & $305 \pm 30$ & $493 \pm 36$ & $584 \pm 25$ & $817 \pm 57$ \\
\hline
\end{tabular}

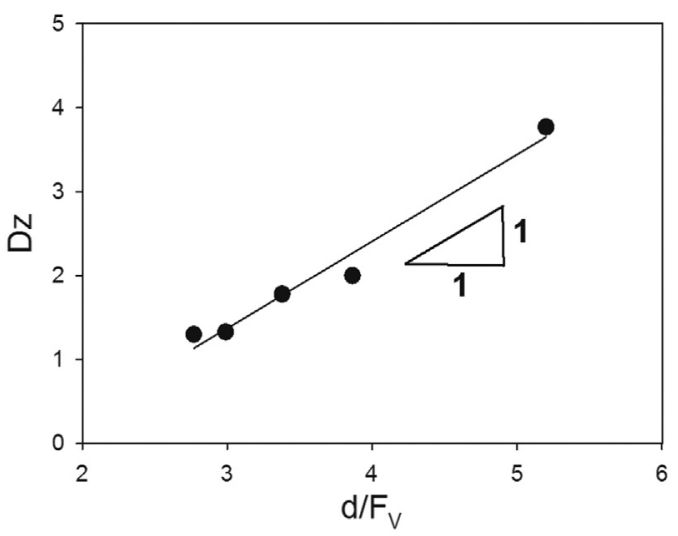

Fig. 9. Dependence of fcc grain size $\left(D_{Z}\right)$ on size / fraction of the particles $\left(d / F_{v}\right)$ ratio.

the particles with $\alpha=1.5$ which is larger than those commonly accepted, however. Usually the value of $\alpha=1.0$, however some authors use $0.25<\alpha<0.5[44,45]$. The obtained increased value of $\alpha$ can be associated with the particles instabilities during grain growth [43]. Nevertheless the linear dependence confirms that the grain growth of the fcc grains was controlled by the Zener pinning effect of the particles due to which the fcc grains remained relatively small $(3.8 \mu \mathrm{m})$ even after $50 \mathrm{~h}$ annealing at $600^{\circ} \mathrm{C}$.

\subsection{Strengthening mechanisms}

The obtained data on mechanical properties of the annealed alloy expectably shows that strength/hardness of the alloy became lower with an increase in the annealing temperature or time while ductility increased (Figs. 5-7) as a result of recrystallization of the cold-worked microstructure (Figs. 1 and 2). However, some increment in strength/ hardness after a short (1-2 h) annealing at low temperatures $\left(500-600^{\circ} \mathrm{C}\right.$ ) seems to be quite unusual. To get better understanding of the microstructure-mechanical properties relationship in the alloy we have performed qualitative analysis of the strengthening mechanisms.

The contribution of different strengthening mechanisms into the overall strength of the alloy can be determined as:

$\sigma=\sigma_{0}+\sigma_{\text {def. }}+\sigma_{D .}+\sigma_{\text {Or. }}$,

where $\sigma_{0}$ is the Pieirls stress, $\sigma_{\text {def. }}$ is the work (cold rolling) strengthening:

$\sigma_{\text {def. }}=\sigma_{0.2}(80 \%$ rolling $) *\left(1-V_{\text {rec. }}\right)$

$\sigma_{D}$. is the grain boundary (Hall-Petch) strengthening:

$\sigma_{D .}=K_{y} * D^{-1 / 2}$

$\sigma_{O r}$. is the precipitation (Orowan) strengthening [46]:

$\sigma_{O r .}=\left(\frac{0.538 G b f^{\frac{1}{2}}}{d}\right) \ln \left(\frac{d}{2 b}\right)$

Here $\sigma_{0.2}$ ( $80 \%$ rolling) is the yield strength of the cold-rolled alloy, $V_{r e c}$ and $D$ are the volume fraction and size of recrystallized fcc grains, respectively, $K_{y}$ - the Hall-Petch coefficient, $G$ - the shear modulus, $b$ is

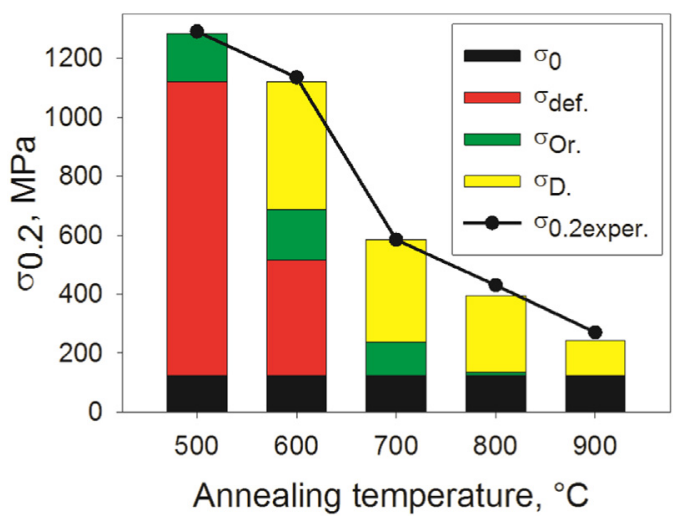

Fig. 10. Contributions of different strengthening mechanisms in the CoCrFeMnNi alloy depending on isochronal $(1 \mathrm{~h})$ annealing temperature.

the Burgers vector, $f$ and $d$ denote, respectively, the fraction and size of the precipitates. The values of $\sigma_{0}=125 \mathrm{MPa}, K_{y}=494 \mathrm{MPa} / \mu \mathrm{m}^{-1 / 2}$, $G=80 \mathrm{GPa}$, and $b=2.58 \times 10^{-10} \mathrm{~m}$ were adopted from [10,31], while $\sigma_{0.2}, V_{\text {rec }}, D, f$, and $d$ were determined experimentally (Tables 1 and 4). The obtained results for the isochronal annealing for $1 \mathrm{~h}$ at $500-900{ }^{\circ} \mathrm{C}$ are shown in Fig. 10.

Fig. 10 shows good agreement between the calculated and the experimental values of the yield strength of the CoCrFeMnNi alloy after annealed at different temperatures. After annealing at $500-600^{\circ} \mathrm{C}$ work hardening $\left(\sigma_{\text {def. }}\right)$ contributes greatly to the overall strength, but the increase in the yield strength in comparison to the cold rolled condition can be attributed to the bcc and sigma phases precipitation $\left(\sigma_{O r}\right)$. Work hardening strengthening diminishes at temperatures of $700{ }^{\circ} \mathrm{C}$ and above due to the formation of a completely recrystallized microstructure (Fig. 2). Also, both precipitation hardening and grain boundary strengthening started to decrease continuously with an increase in the annealing temperature above $700{ }^{\circ} \mathrm{C}$ due to particles/ grains coarsening (Table 1 ). For the precipitation hardening, the decrease in the particles fraction (Table 1) also had a negative effect on strengthening. Overall the graph showed that the highest strength increment after annealing at $700{ }^{\circ} \mathrm{C}$ and $800{ }^{\circ} \mathrm{C}$ was provided by the grain boundaries $\left(\sigma_{D}\right)$. Only in the coarse grain microstructure, which was formed during annealing at $900{ }^{\circ} \mathrm{C}$, grain size strengthening was approximately equal to $\sigma_{0}$.

In the case of the isothermal annealing at $600{ }^{\circ} \mathrm{C}$ softening (Figs. 6-7) is likely to be governed by the same processes: recrystallization and fcc phase grain growth. Coarsening of the sigma phase particles was accompanied by a pronounced increase in their fraction thereby diminishing the $\sigma_{O r}$ effect on strength. Indeed, the calculated values of $\sigma_{O r}$ are $170 \mathrm{MPa}$ and $156 \mathrm{MPa}$ after annealing for 1 and $50 \mathrm{~h}$ at $600{ }^{\circ} \mathrm{C}$, respectively. After $50 \mathrm{~h}$ annealing the greatest contribution was provided by grain boundary strengthening (300 MPa) due to fine $(3.7 \mu \mathrm{m})$ fcc grains (Table 3$)$. The calculated strength (sum of the all strengthening mechanisms contribution) is reasonably close to the experimental value $-580 \mathrm{MPa}$ and $685 \mathrm{MPa}$, respectively.

The attractive combination of strength and ductility of the CoCrFeMnNi alloy after annealing at $600^{\circ} \mathrm{C}$ for $50 \mathrm{~h}$ (Fig. 6) can therefore be mainly attributed to the fine-grained fully recrystallized fcc matrix [47]. However one must keep in mind that the second (mostly, 
sigma) phase particles are responsible for the preserving fine size of fcc grains (Fig. 9) thereby indirectly contributing to high mechanical properties of the alloy. Similar behavior has been recently reported for several other HEAs $[24,48]$.

In summary, the results obtained in the current study have demonstrated that second phase precipitates can have a pronounced effect on the mechanical properties of the CoCrFeMnNi high entropy alloy, widely considered as a single phase alloy. This effect can be direct (via precipitation hardening) or indirect (via pinning of the fcc matrix grain boundaries). The current development strategy of the high-strength HEAs is strongly associated with the finding of a single-phase composition which would be prone to the formation of strengthening second phases due to alloying with additional elements [14]. The results of the present work suggest that HEAs with a single-phase structure stable at high temperatures can be strengthened not only by the alloying but also by a proper thermomechanical/thermal treatment resulting in the formation of precipitates that either directly impede dislocation motion $[19,20]$ or strongly restrict grain growth [24] (Figs. 9-10). It should be noted that recent results show the applicability of such approach not only for the $3 \mathrm{~d}$ transition metals HEAs with an fcc structure, but also for refractory HEAs with a bcc structure like HfNbTaTiZr alloy $[30,49]$.

\section{Conclusions}

In this work, structure and mechanical properties of the CoCrFeMnNi high entropy alloy after cold rolling and subsequent annealing at $500-900{ }^{\circ} \mathrm{C}$ for $1-50 \mathrm{~h}$ were examined. Following conclusions were drawn:

1) Isochronal annealing at $500-900{ }^{\circ} \mathrm{C}$ for $1 \mathrm{~h}$ resulted in recrystallization of the fcc matrix $\left(600-900^{\circ} \mathrm{C}\right)$ and precipitation of the Cr-rich bcc $\left(500-700^{\circ} \mathrm{C}\right)$ and sigma $\left(600-800^{\circ} \mathrm{C}\right)$ particles. The size and fraction of the recrystallized fcc grains and size of the bcc/ sigma particles increased with the annealing temperature. The fraction of the second phase particles exhibited a non-monotonic dependence on the annealing temperature.

2) Isothermal annealing at $600{ }^{\circ} \mathrm{C}$ resulted in the growth of the recrystallized fcc grains and coarsening of both the sigma and bcc particles. Grain growth and sigma particle coarsening can be expressed by power law functions of annealing time with the grain/ particle size exponents of about 3.6 and 4, respectively. Furthermore, it was found that the fcc grain growth was limited by the particles as per the Zener drag mechanism. An increase in the annealing time at $600{ }^{\circ} \mathrm{C}$ from $1-50 \mathrm{~h}$ was also accompanied by a pronounced increase in the fraction of the sigma phase and a decrease in the fraction of the bcc phase.

3) Strength of the alloy increased after annealing for $1 \mathrm{~h}$ at $500{ }^{\circ} \mathrm{C}$ and $600^{\circ} \mathrm{C}$ in comparison with the cold rolled condition, while annealing at higher temperatures resulted in pronounced softening together with increased ductility. The quantitative analysis had revealed that strengthening after annealing at low temperatures was associated with the bcc/sigma particles precipitation.

4) Increase of the annealing time at $600^{\circ} \mathrm{C}$ from $1 \mathrm{~h}$ to $50 \mathrm{~h}$ resulted in softening and increase of ductility. However, even after $50 \mathrm{~h}$ annealing the alloy maintained relatively high strength (yield strength of $685 \mathrm{MPa}$ ) which can be ascribed to the grain boundary (HallPetch) strengthening due to fine fcc grains preserved by pinning effect of the sigma particles.

\section{Acknowledgments}

The authors gratefully acknowledge the financial support from the Russian Science Foundation Grant no. 18-19-00003. The authors are grateful to the personnel of the Joint Research Center, "Technology and Materials”, Belgorod State University, for their assistance.

\section{References}

[1] D.B. Miracle, O.N. Senkov, A critical review of high entropy alloys and related concepts, Acta Mater. 122 (2017) 448-511, https://doi.org/10.1016/j.actamat. 2016.08.081.

[2] B. Cantor, I.T.H. Chang, P. Knight, A.J.B. Vincent, Microstructural development in equiatomic multicomponent alloys, Mater. Sci. Eng. A. 375 (2004) 213-218, https://doi.org/10.1016/j.msea.2003.10.257.

[3] F. Otto, Y. Yang, H. Bei, E.P.P. George, Relative effects of enthalpy and entropy on the phase stability of equiatomic high-entropy alloys, Acta Mater. 61 (2013) 2628-2638, https://doi.org/10.1016/j.actamat.2013.01.042.

[4] F. Otto, A. Dlouhý, K.G. Pradeep, M. Kuběnová, D. Raabe, G. Eggeler, E.P. George, Decomposition of the single-phase high-entropy alloy CrMnFeCoNi after prolonged anneals at intermediate temperatures, Acta Mater. 112 (2016), https://doi.org/10. 1016/j.actamat.2016.04.005.

[5] E.J. Pickering, R. Muñoz-Moreno, H.J. Stone, N.G. Jones, Precipitation in the equiatomic high-entropy alloy CrMnFeCoNi, Scr. Mater. 113 (2016), https://doi. org/10.1016/j.scriptamat.2015.10.025.

[6] B. Schuh, F. Mendez-Martin, B. Völker, E.P. George, H. Clemens, R. Pippan, A. Hohenwarter, Mechanical properties, microstructure and thermal stability of a nanocrystalline CoCrFeMnNi high-entropy alloy after severe plastic deformation, Acta Mater. 96 (2015) 258-268, https://doi.org/10.1016/j.actamat.2015.06.025.

[7] N.D. Stepanov, D.G. Shaysultanov, M.S. Ozerov, S.V. Zherebtsov, G.A. Salishchev, Second phase formation in the CoCrFeNiMn high entropy alloy after recrystallization annealing, Mater. Lett. 185 (2016) 1-4, https://doi.org/10.1016/j.matlet. 2016.08.088.

[8] W. Zhou, L.M. Fu, P. Liu, X.D. Xu, B. Chen, G.Z. Zhu, X.D. Wang, A.D. Shan, M.W. Chen, Deformation stimulated precipitation of a single-phase CoCrFeMnNi high entropy alloy, Intermetallics 85 (2017) 90-97, https://doi.org/10.1016/j. intermet.2017.02.010.

[9] A. Gali, E.P. George, Tensile properties of high- and medium-entropy alloys, Intermetallics 39 (2013) 74-78, https://doi.org/10.1016/j.intermet.2013.03.018.

[10] F. Otto, A. Dlouhý, C. Somsen, H. Bei, G. Eggeler, E.P. George, The influences of temperature and microstructure on the tensile properties of a $\mathrm{CoCrFeMnNi}$ highentropy alloy, Acta Mater. 61 (2013) 5743-5755, https://doi.org/10.1016/j actamat.2013.06.018.

[11] B. Gludovatz, A. Hohenwarter, D. Catoor, E.H. Chang, E.P. George, R.O. Ritchie, A fracture-resistant high-entropy alloy for cryogenic applications, Science 345 (2014) 1153-1158, https://doi.org/10.1126/science.1254581.

[12] J.Y. He, H. Wang, H.L. Huang, X.D. Xu, M.W. Chen, Y. Wu, X.J. Liu, T.G. Nieh, K. An, Z.P. Lu, A precipitation-hardened high-entropy alloy with outstanding tensile properties, Acta Mater. 102 (2016) 187-196, https://doi.org/10.1016/j.actamat. 2015.08.076.

[13] Y.Y. Zhao, H.W. Chen, Z.P. Lu, T.G. Nieh, Thermal stability and coarsening of coherent particles in a precipitation-hardened (NiCoFeCr)94Ti2Al4 high-entropy alloy, Acta Mater. 147 (2018) 184-194, https://doi.org/10.1016/J.ACTAMAT 2018.01.049.

[14] W.H. Liu, T. Yang, C.T. Liu, Precipitation hardening in CoCrFeNi-based high entropy alloys, Mater. Chem. Phys. (2017), https://doi.org/10.1016/j.matchemphys. 2017.07.037.

[15] N.D. Stepanov, N.Y. Yurchenko, M.A. Tikhonovsky, G.A. Salishchev, Effect of carbon content and annealing on structure and hardness of the CoCrFeNiMn-based high entropy alloys, J. Alloy. Compd. 687 (2016) 59-71, https://doi.org/10.1016/j. jallcom.2016.06.103.

[16] N. Kashaev, V. Ventzke, N. Stepanov, D. Shaysultanov, V. Sanin, S. Zherebtsov, Laser beam welding of a CoCrFeNiMn-type high entropy alloy produced by selfpropagating high-temperature synthesis, Intermetallics 96 (2018) 63-71, https:// doi.org/10.1016/j.intermet.2018.02.014.

[17] B. Gwalani, V. Soni, M. Lee, S. Mantri, Y. Ren, R. Banerjee, Optimizing the coupled effects of Hall-Petch and precipitation strengthening in a $\mathrm{Al0} .3 \mathrm{CoCrFeNi}$ high entropy alloy, Mater. Des. 121 (2017) 254-260, https://doi.org/10.1016/j.matdes. 2017.02.072

[18] B. Gwalani, S. Gorsse, D. Choudhuri, M. Styles, Y. Zheng, R.S. Mishra, R. Banerjee, Modifying transformation pathways in high entropy alloys or complex concentrated alloys via thermo-mechanical processing, Acta Mater. 153 (2018) 169-185, https:// doi.org/10.1016/J.ACTAMAT.2018.05.009.

[19] K. Ming, X. Bi, J. Wang, Realizing strength-ductility combination of coarse-grained Al0.2Co1.5CrFeNi1.5Ti0.3alloy via nano-sized, coherent precipitates, Int. J. Plast. 100 (2018) 177-191, https://doi.org/10.1016/j.ijplas.2017.10.005.

[20] M.V. Klimova, D.G. Shaysultanov, R.S. Chernichenko, V.N. Sanin, N.D. Stepanov, S.V. Zherebtsov, A.N. Belyakov, Recrystallized microstructures and mechanical properties of a C-containing CoCrFeNiMn-type high-entropy alloy, Mater. Sci. Eng. A. 740-741 (2019) 201-210, https://doi.org/10.1016/J.MSEA.2018.09.113.

[21] N.D. Stepanov, D.G. Shaysultanov, G.A. Salishchev, M.A. Tikhonovsky, E.E. Oleynik, A.S. Tortika, O.N. Senkov, Effect of V content on microstructure and mechanical properties of the CoCrFeMnNiVx high entropy alloys, J. Alloy. Compd. 628 (2015) 170-185, https://doi.org/10.1016/j.jallcom.2014.12.157.

[22] Y.H. Jo, W.-M. Choi, S.S. Sohn, H.S. Kim, B.-J. Lee, S. Lee, Role of brittle sigma phase in cryogenic-temperature-strength improvement of non-equi-atomic Fe-rich VCrMnFeCoNi high entropy alloys, Mater. Sci. Eng. A. 724 (2018) 403-410, https://doi.org/10.1016/J.MSEA.2018.03.115.

[23] J.W. Bae, J. Moon, M.J. Jang, D. Yim, D. Kim, S. Lee, H.S. Kim, Trade-off between tensile property and formability by partial recrystallization of $\mathrm{CrMnFeCoNi}$ highentropy alloy, Mater. Sci. Eng. A. 703 (2017) 324-330, https://doi.org/10.1016/J. MSEA.2017.07.079. 
[24] N.D. Stepanov, D.G. Shaysultanov, R.S. Chernichenko, D.M. Ikornikov, V.N. Sanin, S.V. Zherebtsov, Mechanical properties of a new high entropy alloy with a duplex ultra-fine grained structure, Mater. Sci. Eng. A. 728 (2018) 54-62, https://doi.org/ 10.1016/j.msea.2018.04.118.

[25] H.Y. Yasuda, H. Miyamoto, K. Cho, T. Nagase, Formation of ultrafine-grained microstructure in Al0.3CoCrFeNi high entropy alloys with grain boundary precipitates, Mater. Lett. 199 (2017) 120-123, https://doi.org/10.1016/J.MATLET. 2017.04.072.

[26] K. Liu, M. Komarasamy, B. Gwalani, S. Shukla, R.S. Mishra, Fatigue behavior of ultrafine grained triplex Al0.3CoCrFeNi high entropy alloy, Scr. Mater. 158 (2019) 116-120, https://doi.org/10.1016/J.SCRIPTAMAT.2018.08.048.

[27] W.H. Liu, Y. Wu, J.Y. He, T.G. Nieh, Z.P. Lu, Grain growth and the Hall-Petch relationship in a high-entropy FeCrNiCoMn alloy, Scr. Mater. 68 (2013) 526-529, https://doi.org/10.1016/j.scriptamat.2012.12.002.

[28] F. Otto, N.L. Hanold, E.P. George, Microstructural evolution after thermomechanical processing in an equiatomic, single-phase CoCrFeMnNi high-entropy alloy with special focus on twin boundaries, Intermetallics 54 (2014) 39-48, https://doi.org/10.1016/j.intermet.2014.05.014.

[29] Z. Wu, H. Bei, F. Otto, G.M. Pharr, E.P. George, Recovery, recrystallization, grain growth and phase stability of a family of FCC-structured multi-component equiatomic solid solution alloys, Intermetallics 46 (2014), https://doi.org/10.1016/j. intermet.2013.10.024.

[30] O.N. Senkov, A.L. Pilchak, S.L. Semiatin, Effect of cold deformation and annealing on the microstructure and tensile properties of a HfNbTaTiZr refractory high entropy alloy, Metall. Mater. Trans. A. (2018) 1-17, https://doi.org/10.1007/s11661018-4646-8.

[31] N. Stepanov, M. Tikhonovsky, N. Yurchenko, D. Zyabkin, M. Klimova, S. Zherebtsov, A. Efimov, G. Salishchev, Effect of cryo-deformation on structure and properties of CoCrFeNiMn high-entropy alloy, Intermetallics 59 (2015) 8-17, https://doi.org/10.1016/j.intermet.2014.12.004.

[32] P.A. Beck, J.C. Kremer, L. Demer, Grain growth in high purity aluminum, Phys. Rev. 71 (1947), https://doi.org/10.1103/PhysRev.71.555 (555-555).

[33] P.P. Bhattacharjee, G.D. Sathiaraj, M. Zaid, J.R. Gatti, C. Lee, C.W. Tsai, J.W. Yeh, Microstructure and texture evolution during annealing of equiatomic CoCrFeMnNi high-entropy alloy, J. Alloy. Compd. 587 (2014) 544-552, https://doi.org/10. 1016/j.jallcom.2013.10.237.

[34] G.D. Sathiaraj, M.Z. Ahmed, P.P. Bhattacharjee, Microstructure and texture of heavily cold-rolled and annealed fcc equiatomic medium to high entropy alloys, J. Alloy. Compd. 664 (2016) 109-119, https://doi.org/10.1016/j.jallcom.2015.12. 172.

[35] J.E. Saal, I.S. Berglund, J.T. Sebastian, P.K. Liaw, G.B. Olson, Equilibrium high entropy alloy phase stability from experiments and thermodynamic modeling, Scr. Mater. 146 (2018) 5-8, https://doi.org/10.1016/J.SCRIPTAMAT.2017.10.027.

[36] N.D. Stepanov, D.G. Shaysultanov, R.S. Chernichenko, M.A. Tikhonovsky, S.V. Zherebtsov, Effect of $\mathrm{Al}$ on structure and mechanical properties of Fe-Mn-Cr-Ni$\mathrm{Al}$ non-equiatomic high entropy alloys with high Fe content, J. Alloy. Compd. 770 (2018) 194-203, https://doi.org/10.1016/j.jallcom.2018.08.093.

[37] C.-C. Hsieh, W. Wu, Overview of intermetallic sigma ( ) phase precipitation in stainless steels, ISRN Metall. 2012 (2012) 1-16, https://doi.org/10.5402/2012/ 732471.

[38] E.O. Hall, S.H. Algie, The sigma phase, Metall. Rev. 11 (1966) 61-88, https://doi. org/10.1179/mtlr.1966.11.1.61.

[39] M. Hillert, On the theory of normal and abnormal grain growth, Acta Metall. 13 (1965) 227-238, https://doi.org/10.1016/0001-6160(65)90200-2.

[40] A. Ardell, On the coarsening of grain boundary precipitates, Acta Metall. 20 (1972) 601-609, https://doi.org/10.1016/0001-6160(72)90015-6.

[41] G.S. Rohrer, Introduction to grains, phases, and interfaces-an interpretation of microstructure (by C.S. Smith, Metall. Mater. Trans. A. 41 (2010) 1063-1100), Trans. AIME 175 (1948) 15-51, https://doi.org/10.1007/s11661-010-0215-5.

[42] W.B. Hutchinson, B.J. Duggan, Influence of precipitation on recrystallization and texture development in an iron-1.2\% copper alloy, Met. Sci. 12 (1978) 372-380, https://doi.org/10.1179/msc.1978.12.8.372.

[43] F.J. Humphreys, M. Hatherly, Recrystallization and Related Annealing Phenomena, Elsevier, 2004.

[44] N. Louat, The resistance to normal grain growth from a dispersion of spherical particles, Acta Metall. 30 (1982) 1291-1294, https://doi.org/10.1016/00016160(82)90147-X.

[45] M. Hillert, Inhibition of grain growth by second-phase particles, Acta Metall. 36 (1988) 3177-3181, https://doi.org/10.1016/0001-6160(88)90053-3.

[46] T. Gladman, Precipitation hardening in metals, Mater. Sci. Technol. 15 (1999) 30-36, https://doi.org/10.1179/026708399773002782.

[47] S.J. Sun, Y.Z. Tian, H.R. Lin, X.G. Dong, Y.H. Wang, Z.J. Zhang, Z.F. Zhang, Enhanced strength and ductility of bulk CoCrFeMnNi high entropy alloy having fully recrystallized ultrafine-grained structure, Mater. Des. 133 (2017) 122-127, https://doi.org/10.1016/j.matdes.2017.07.054.

[48] Z. Wang, A. Genc, I. Baker, Direct versus indirect particle strengthening in a strong, ductile FeNiMnAlTi high entropy alloy, Mater. Charact. 132 (2017) 156-161, https://doi.org/10.1016/J.MATCHAR.2017.08.019.

[49] N.D. Stepanov, N.Y. Yurchenko, S.V. Zherebtsov, M.A. Tikhonovsky, G.A. Salishchev, Aging behavior of the HfNbTaTiZr high entropy alloy, Mater. Lett. 211 (2018) 87-90, https://doi.org/10.1016/j.matlet.2017.09.094. 